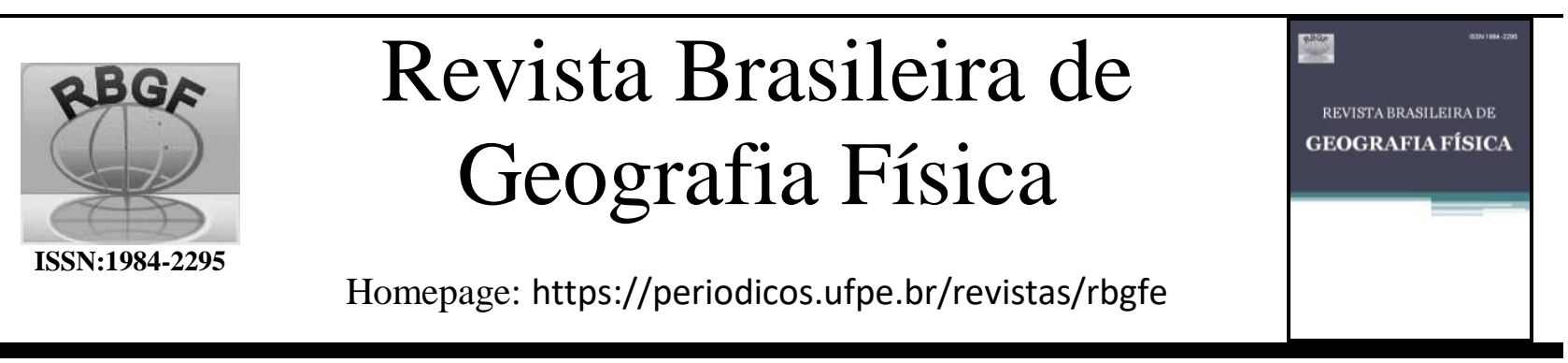

\title{
Delimitação e caracterização morfométrica da bacia hidrográfica do Riacho do Navio, Pernambuco, a partir de dados SRTM processados no QGIS*
}

\author{
Ênio Gomes Flôr Souza ${ }^{1}$, Antônio Henrique Cardoso do Nascimento ${ }^{2}$, Ellen Abreu da Cruz ${ }^{4}$, Dalbert de \\ Freitas Pereira ${ }^{5}$, Raquel Soares da Silva ${ }^{6}$, Thiago Pereira da Silva ${ }^{7}$, Winandy Araújo Freire ${ }^{8}$
}

\begin{abstract}
${ }^{1}$ Professor do Curso de Engenharia Agronômica do Instituto Federal de Alagoas (IFAL). Campus Piranhas, CEP: 57.460-000, Piranhas (AL), Brasil, Tel.: (+55 87) 99637-1428, enio.souza@ ifal.edu.br (autor correspondente). ${ }^{3}$ Professor dos Cursos de Engenharia Agronômica, Engenharia de Pesca e Zootecnia da Universidade Federal Rural de Pernambuco (UFRPE). Unidade Acadêmica de Serra Talhada (UAST), CEP 56.909-535, Serra Talhada (PE), Brasil, Tel.: (+55 87) 98852-5129, tonyagronomia@ gmail.com. ${ }^{4}$ Professora do Curso de Engenharia Agronômica do Instituto Federal de Alagoas (IFAL). Campus Piranhas, CEP: 57.460-000, Piranhas (AL), Brasil, Tel.: (+55 73) 99111-2933, ellen.cruz @ ifal.edu.br. ${ }^{5}$ Graduando em Engenharia Agronômica do Instituto Federal de Alagoas (IFAL). Campus Piranhas, CEP: 57.460-000, Piranhas (AL), Brasil, Tel.: (+55 82) 98887-4576, dalbert.freitas@gmail.com. ${ }^{6}$ Graduanda em Engenharia Agronômica do Instituto Federal de Alagoas (IFAL). Campus Piranhas, CEP: 57.460-000, Piranhas (AL), Brasil, Tel.: (+55 82) 98108-6714, raquel.ssm16@ hotmail.com. ${ }^{7}$ Graduando em Engenharia Agronômica do Instituto Federal de Alagoas (IFAL). Campus Piranhas, CEP: 57.460-000, Piranhas (AL), Brasil, Tel.: (+55 82) 98855-9531, thiagopdseng@ gmail.com. ${ }^{8}$ Graduando em Engenharia Agronômica do Instituto Federal de Alagoas (IFAL). Campus Piranhas, CEP: 57.460-000, Piranhas (AL), Brasil, Tel.: (+55 82) 98751-5914, araujo.winandy@gmail.com. * Trabalho de conclusão de curso do primeiro autor, apresentado ao Curso de Especialização em Georreferenciamento e Geoprocessamento do Instituto Nacional de Ensino e Pesquisa (INESP).
\end{abstract}

Artigo recebido em 04/04/2020 e aceito em 29/06/2021

\section{R E S U M O}

A bacia hidrográfica do Riacho do Navio, em Pernambuco, tem importante papel ao atender as demandas hídricas de animais, culturas agrícolas e da população local, sendo fundamental estudá-la de maneira mais específica, a fim de que sejam geradas informações que subsidiem a gestão de seus recursos ambientais. O objetivo deste estudo foi delimitar a bacia hidrográfica do Riacho do Navio e descrever suas características morfométricas (forma, rede de drenagem e relevo) a partir de dados Shuttle Radar Topography Mission (SRTM) processados no programa livre Quantum GIS (QGIS), via a ferramenta Terrain Analysis Using Digital Elevation Models (TauDEM). A bacia em questão possui 3.312,97 km², sendo considerada de quinta ordem, com densidade de drenagem de $0,50 \mathrm{~km} \mathrm{~km}^{-2}$. Observou-se que a declividade média foi de $5,23 \%$, sendo que mais de $86,61 \%$ da área da bacia apresentou declividades menores que $8 \%$. O fator de forma, o coeficiente de compacidade e o índice de circularidade atingiram valores de 0,$29 ; 2,10$ e 0,22 , indicando que a bacia possui formato alongado e, por conseguinte, baixa tendência a enchentes. Por outro lado, a sinuosidade e a declividade média do álveo podem favorecer a ocorrência de cheias em situações de chuvas intensas. O uso do QGIS e do TauDEM para tratamento de imagens SRTM se mostrou uma ferramenta eficiente, podendo auxiliar na gestão e no gerenciamento dos recursos hídricos da bacia do Riacho do Navio.

Palavras-chave: análise fisiográfica, Hidrologia, modelo digital de elevação, Semiárido, TauDEM.

\section{Delimitation and morphometric characterization of the hydrographic basin of Riacho do Navio, Pernambuco, based on SRTM data processed at QGIS}

\begin{abstract}
A B S T R A C T
The Riacho do Navio watershed, in Pernambuco, has an important role in meeting the water demands of animals, agricultural crops and the local population, and it is essential to study it more specifically, in order to generate information that supports the management of its environmental resources. The objective of this study was to delimit the Riacho do Navio watershed and describe its morphometric characteristics (shape, drainage network and relief) from Shuttle Radar Topography Mission (SRTM) data, processed in the free program Quantum GIS (QGIS), via the Terrain Analysis Using Digital Elevation Models (TauDEM) tool. The watershed in question has 3,312.97 $\mathrm{km}^{2}$, being considered of fifth order, with drainage density of $0.50 \mathrm{~km} \mathrm{~km}^{-2}$. It was observed that the average slope was $5.23 \%$, with more than $86.61 \%$ of the watershed area showing slopes less than $8 \%$. The shape factor, the compactness coefficient and the circularity index reached values of $0.29 ; 2.10$ and 0.22 , indicating that the watersehd has an elongated shape and, therefore, low tendency
\end{abstract}


to flooding. On the other hand, the sinuosity and the average slope of the riverbed can favor the occurrence of floods in situations of intense rains. The use of QGIS and TauDEM for the treatment of SRTM images proved to be an efficient tool, which can assist in the management and administration of water resources in the Riacho do Navio watershed. Keywords: physiographic analysis, Hydrology, digital elevation model, Semiarid, TauDEM.

\section{Introdução}

A bacia hidrográfica é uma área de captação natural da água da precipitação que faz convergir os escoamentos para um único ponto de saída, seu exutório (Tucci, 2015, Rocha e Santos, 2018). Espacialmente, a bacia hidrográfica é delimitada por um divisor topográfico, que consiste em uma linha que passa pelos pontos mais altos do terreno (topos de morros), ao redor de uma rede de drenagem (Silva, 2015).

Um dos maiores entraves na adoção e proposição metodológica das bacias hidrográficas, enquanto unidades espaciais para o planejamento ambiental integrado, reside nas suas múltiplas dimensões e expressões espaciais (Botelho e Silva, 2004). Entretanto, dentre as principais ferramentas computacionais do Geoprocessamento está o Sistema de Informação Geográfica (SIG), o qual possibilita a realização de análises complexas, ao integrar dados de várias fontes e criar banco de dados georreferenciados, no qual possibilitam a automatização da produção de materiais cartográficos (Silva, Mariani e González, 2012; Sánchez, Chávez e Gonzalez et al., 2019).

Com as aplicações do SIG, a geração de modelos digitais de elevação (MDE) a partir de dados Shuttle Radar Topography Mission (SRTM) permite a reprodução com exatidão do caminho preferencial de escoamento da água superficial (Medeiros, Ferreira e Ferreira, 2009; Alves Sobrinho et al., 2010; Schmitt e Moreira, 2015, Rodrigues et al., 2018; Girão, et al., 2019; Gomes et al., 2020) e, assim, podem ser derivadas características e índices físicos de uma bacia hidrográfica de forma mais precisa, tais como a forma, as dimensões, o sistema de drenagem e o relevo, os quais são fundamentais para o estabelecimento de estratégias de gestão sustentável dos recursos hídricos de uma unidade territorial (Brasil, 1997; Martins et al., 2021; Toniolo et al., 2021).

Quanto ao emprego de geotecnologias para a delimitação de bacias hidrográficas, percebe-se, na literatura, a busca pela utilização de programas livres, como o Quantum GIS - QGIS (QGIS, 2020), o qual permite a automação dos processos de extração das características do meio físico com elevada eficiência, proporcionando economia de tempo (Silva et al., 2018; Fernandes, Oliveira e
Rocha, 2018; Flenniken, Stuglik e Iannone, 2020). Associado ao QGIS, alguns autores, como Schmitt e Moreira (2015), Costa, Souza e Silva (2016) e Pontes et al. (2019) delimitaram automaticamente bacias hidrográficas com o auxílio da ferramenta gratuita Terrain Analysis Using Digital Elevation Models - TauDEM (Tarboton, 2020), que possibilita extrair informações hidrológicas da topografia por meio do MDE.

$\mathrm{O}$ estudo de caso apresentado neste artigo refere-se à área de drenagem do Riacho do Navio, a qual se insere na bacia do rio Pajeú, a maior do estado de Pernambuco, possuindo uma área de $16.685,63 \mathrm{~km}^{2}$, correspondendo a $16,97 \%$ da área do Estado (APAC, 2020). Na literatura, há trabalhos sobre a caracterização morfométrica da bacia hidrográfica do rio Pajeú (Feitosa, Santos e Araújo, 2011; Oliveira et al., 2012; Ferreira et al., 2014; Ribeiro, 2016), porém são escassas as informações hidrológicas específicas sobre a área de contribuição do Riacho do Navio (Nouvelot, Ferreira e Cadier, 1979; Falcão e Leal, 1980; Cadier, 1994), sendo fundamental o levantamento desses dados para fins de projeção de uso do manancial em políticas públicas importantes, como na gestão atual de suas águas e na sua perenização a partir do Projeto de Transposição do Rio São Francisco (Souza, 2019).

Assim, o objetivo deste estudo foi delimitar a bacia hidrográfica do Riacho do Navio e descrever suas características e índices morfométricos (forma, rede de drenagem e relevo) a partir de dados SRTM processados no programa livre QGIS, via a ferramenta TauDEM.

\section{Material e métodos}

Caracterização da área de estudo

A área de análise e estudo morfométrico corresponde à bacia hidrográfica do Riacho do Navio, localizada nas coordenadas geográficas entre $08^{\circ} 03^{\prime} 55,51^{\prime \prime}$ e $08^{\circ} 42^{\prime} 22,5^{\prime}$ " de latitude sul, e $37^{\circ} 46^{\prime} 10,56^{\prime \prime}$ e $38^{\circ} 34^{\prime} 43,32^{\prime \prime}$ de longitude oeste, abrangendo parte dos municípios de Floresta, Betânia, Custódia e Ibimirim, no Estado de Pernambuco (Figura 1). A bacia do Riacho do Navio, por sua vez, está inserida na bacia hidrográfica do rio Pajeú, porção Centro-Oeste de 
Pernambuco. Tem uma área de drenagem de $3.312,97 \mathrm{~km}^{2}$, perímetro de $432,48 \mathrm{~km}, 140,78 \mathrm{~km}$ de comprimento do curso d'água principal e tem sua foz no rio Pajeú na cidade de Floresta. O curso do Riacho do Navio tem a direção no sentido nordeste-sudoeste.

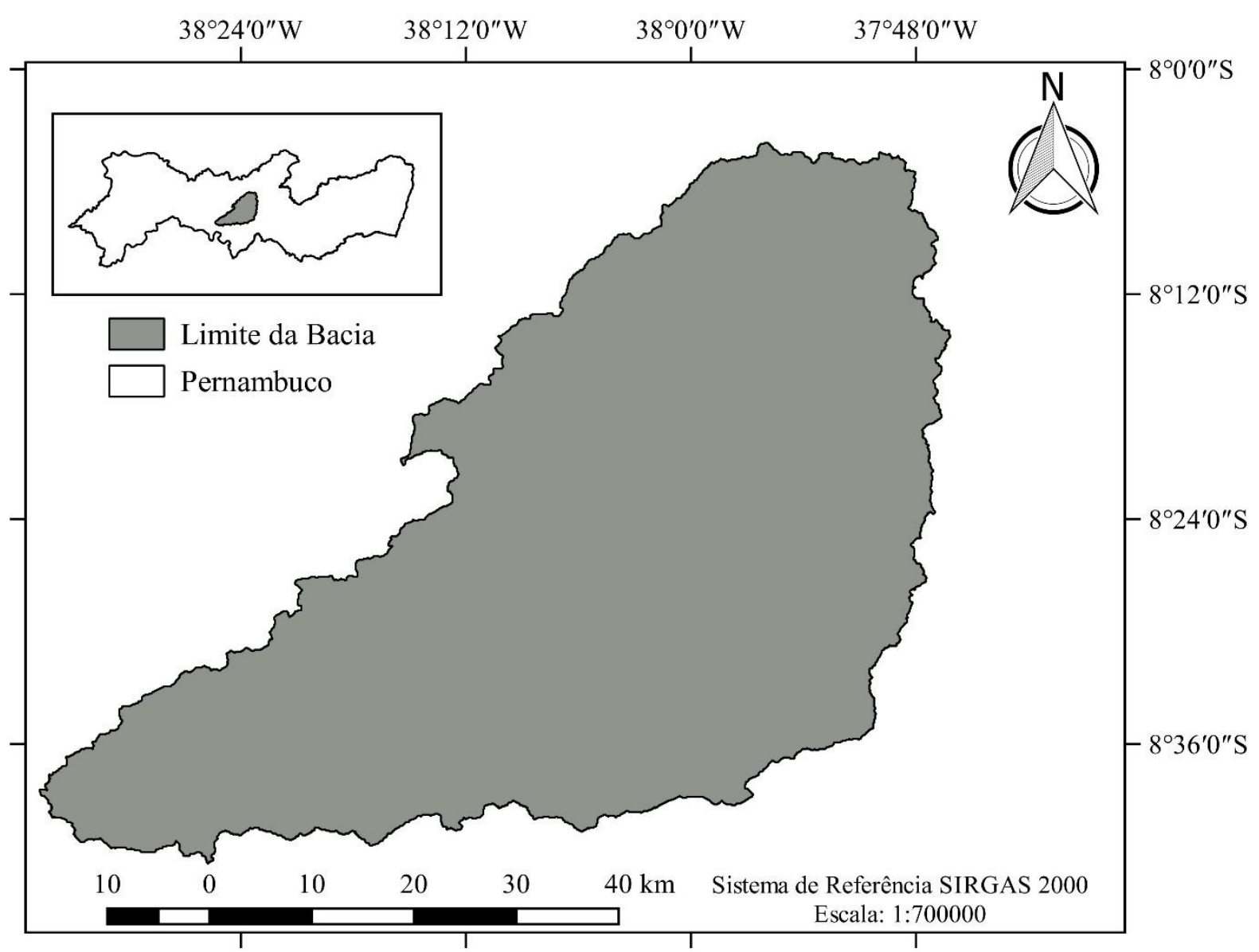

Figura 1. Mapa de localização da bacia hidrográfica do Riacho do Navio, Pernambuco.

Processamento dos dados SRTM

Obteve-se os dados SRTM junto à Embrapa Monitoramento por Satélite (Miranda, 2005), utilizando a carta SC-24-X-A, cujos dados altimétricos apresentam resolução espacial de $90 \mathrm{~m}$ x $90 \mathrm{~m}$. Para a extração das redes de drenagem, o MDE passou pelos tratamentos descritos abaixo com o auxílio dos programas livres QGIS versão 2.18.7 e TauDEM versão 5.3.7, sendo este composto por ferramentas para a extração e análise de informações hidrológicas.

Inicialmente foram eliminados os pixels sem valores de elevação, originando um novo MDE. A partir de então foi possível gerar os mapas com as informações de direções de fluxo e de declividade. Tais informações foram necessárias para a composição do mapa da área de contribuição de fluxo. Com a origem deste, pode-se obter a área de contribuição correspondente aos limites da bacia hidrográfica determinado a partir do ponto exutório, permitindo a primeira visualização da rede de drenagem (Lopes, Leal e Ramos, 2018).
A definição dos corpos hídricos passou por um reajuste do limiar que se refere ao número mínimo de células do terreno necessárias para gerar pixels da drenagem, permitindo a extração do fluxo e de drenagem. Rennó et al. (2008), estudando a variação do limiar, observou que índice para verificação hidrológica acima do limiar de 300 foi o mais indicado. Assim para este estudo foi adotado também o valor de limiar indicado pelos autores na extração do fluxo de drenagem.

Diante do reajuste do limiar, obteve-se a hierarquia dos rios, as sub-bacias e a rede de drenagem. O método utilizado para demarcação automática dos limites da bacia hidrográfica do Riacho do Navio foi de acordo com classificação da hierarquização fluvial proposta por Strahler (1957). Assim, finalizou-se a etapa de geração de mapas e iniciou-se a caracterização da bacia e subbacias, que ocorreu utilizando recursos de sistemas de informações geográficas (SIG) e as equações da Tabela 1. 
A caracterização foi realizada por meio de cálculos geométricos que relacionaram as principais medidas da bacia como área de drenagem, perímetro, comprimento do eixo Tabela 1. Equações para cálculo dos índices geométricos, hidrográficos e de relevo, utilizados para a caracterização morfométrica da bacia hidrográfica do Riacho do Navio, Pernambuco.

\begin{tabular}{|c|c|c|c|}
\hline PARÂMETRO & DESCRIÇÃO & EQUAÇÃO & FONTE \\
\hline \multicolumn{4}{|c|}{ CARACTERÍSTICAS GEOMÉTRICAS } \\
\hline Coeficiente de compacidade $(\mathrm{Kc})$ & $\begin{array}{l}\text { Relação entre o perímetro }(\mathrm{P}, \mathrm{km}) \text { da bacia e a área da bacia } \\
\left(\mathrm{A}, \mathrm{km}^{2}\right) .\end{array}$ & $\mathrm{Kc}=0,28\left(\mathrm{P} / \mathrm{A}^{0,5}\right)$ & Lima (1969) \\
\hline Fator de forma $(\mathrm{Kf})$ & $\begin{array}{l}\text { Relação entre a área da bacia }\left(\mathrm{A}, \mathrm{km}^{2}\right) \text { e o comprimento do } \\
\text { eixo da bacia }(\mathrm{L}, \mathrm{km}) \text {. }\end{array}$ & $\mathrm{Kf}=\mathrm{A} / \mathrm{L}^{2}$ & Horton (1945) \\
\hline \multicolumn{4}{|c|}{ CARACTERÍSTICAS GEOMÉTRICAS } \\
\hline Índice de circularidade (Ic) & $\begin{array}{l}\text { Relação entre a área da bacia }\left(\mathrm{A}, \mathrm{km}^{2}\right) \text { e o perímetro }(\mathrm{P}, \mathrm{km}) \\
\text { da bacia. }\end{array}$ & $\mathrm{Ic}=12,57\left(\mathrm{~A} / \mathrm{P}^{2}\right)$ & Müller (1953) \\
\hline Razão de elongação (Re) & $\begin{array}{l}\text { Relação entre índices pré determinados, a área da bacia (A, } \\
\left.\mathrm{km}^{2}\right) \text { e o comprimento do eixo da bacia }(\mathrm{L}, \mathrm{km}) \text {. }\end{array}$ & $\begin{array}{l}\operatorname{Re}=1,128 \\
\left.\left[\left(\mathrm{~A}^{0,5}\right) / \mathrm{L}\right)\right]\end{array}$ & Schumm (1963) \\
\hline \multicolumn{4}{|c|}{ CARACTERÍSTICAS HIDROGRÁFICAS } \\
\hline $\begin{array}{l}\text { Densidade de drenagem (Dd, } \mathrm{km} \\
\mathrm{km}^{-2} \text { ) }\end{array}$ & $\begin{array}{l}\text { Relação entre o comprimento da rede de drenagem }(\mathrm{Rd}, \mathrm{km}) \text { e } \\
\text { a área da bacia }\left(\mathrm{A}, \mathrm{km}^{2}\right) \text {. }\end{array}$ & $\mathrm{Dd}=\mathrm{Rd} / \mathrm{A}$ & Horton (1945) \\
\hline Densidade hidrográfica $\left(\mathrm{Dh}, \mathrm{km}^{-2}\right)$ & $\begin{array}{l}\text { Relação entre o número de segmentos de rios }(\mathrm{Nt}) \text { e a área da } \\
\text { bacia }\left(\mathrm{A}, \mathrm{km}^{2}\right) .\end{array}$ & $\mathrm{Dh}=\mathrm{Nt} / \mathrm{A}$ & Christofoletti (1969) \\
\hline $\begin{array}{l}\text { Extensão média do escoamento } \\
\text { superficial }(\mathrm{Lm}, \mathrm{km})\end{array}$ & $\begin{array}{l}\text { Relação entre a área da bacia }\left(\mathrm{A}, \mathrm{km}^{2}\right) \text { e o comprimento da } \\
\text { rede de drenagem }(\mathrm{Rd}, \mathrm{km}) \text {. }\end{array}$ & $\mathrm{Lm}=\mathrm{A} / 4 \mathrm{Rd}$ & $\begin{array}{l}\text { Villela e Matos } \\
(1975)\end{array}$ \\
\hline $\begin{array}{l}\text { Índice de sinuosidade do rio } \\
\text { principal (Is, \%) }\end{array}$ & $\begin{array}{l}\text { Relação entre o comprimento rio principal }(\mathrm{R}, \mathrm{km}) \text { e o } \\
\text { comprimento do talvegue do rio principal }(\mathrm{Lrp}, \mathrm{km}) \text {. }\end{array}$ & Is $=100(\mathrm{R}-\mathrm{Lrp}) / \mathrm{R}$ & Schumm (1963) \\
\hline Sinuosidade do rio principal (Srp) & $\begin{array}{l}\text { Relação entre o comprimento rio principal }(\mathrm{R}, \mathrm{km}) \text { e o } \\
\text { comprimento do talvegue do rio principal }(\mathrm{Lrp}, \mathrm{km}) \text {. }\end{array}$ & $\operatorname{Srp}=\mathrm{R} / \mathrm{Lrp}$ & Schumm (1963) \\
\hline Razão de textura $\left(\mathrm{T}, \mathrm{km}^{-1}\right)$ & $\begin{array}{l}\text { Relação entre o número de segmentos de rios }(\mathrm{Nt}) \text { e o } \\
\text { perímetro da bacia }(\mathrm{P}, \mathrm{km}) \text {. }\end{array}$ & $\mathrm{T}=\mathrm{Nt} / \mathrm{P}$ & $\begin{array}{l}\text { Smith } \quad(1950) \\
\text { França (1968) }\end{array}$ \\
\hline \multicolumn{4}{|c|}{ CARACTERÍSTICAS DO RELEVO } \\
\hline $\begin{array}{l}\text { Declividade do rio principal }\left(\mathrm{m} \mathrm{m}^{-}\right. \\
\left.{ }^{1}\right)\end{array}$ & $\begin{array}{l}\text { Relação da variação da cota }(\Delta \mathrm{H}) \text { e do comprimento do rio } \\
\text { principal }(\mathrm{R}) ;\end{array}$ & $\begin{array}{l}\mathrm{S} 1=\left(\operatorname{Cota}_{\max }-\right. \\
\left(\operatorname{Cota}_{\min }\right) / \mathrm{R}\end{array}$ & $\begin{array}{l}\text { Villela e Matos } \\
(1975)\end{array}$ \\
\hline Índice de rugosidade (Ir) & $\begin{array}{l}\text { Relação entre a amplitude altimétrica }(\Delta \mathrm{H}, \mathrm{km}) \text { e a Densidade } \\
\text { de drenagem }\left(\mathrm{Dd}, \mathrm{km} \mathrm{km}^{-2}\right) \text {. }\end{array}$ & $\mathrm{Ir}=\Delta \mathrm{H}^{*} \mathrm{Dd}$ & Christofoletti (1969) \\
\hline Razão de relevo (Rr) & $\begin{array}{l}\text { Relação entre a amplitude altimétrica }(\Delta \mathrm{H}, \mathrm{km}) \text { e o } \\
\text { comprimento do eixo da bacia }(\mathrm{L}, \mathrm{km}) \text {. }\end{array}$ & $\mathrm{Rr}=\Delta \mathrm{H} / \mathrm{L}$ & Christofoletti (1969) \\
\hline
\end{tabular}

Para as características da hidrografia, que relacionam as principais medidas da rede hidrográfica da bacia, foram determinados o ordenamento dos canais por hierarquia segundo Strahler (1957), o comprimento da rede de drenagem, o comprimento do rio principal, o comprimento do talvegue do rio principal, a densidade de drenagem, a densidade hidrográfica, extensão média do escoamento superficial, o índice de sinuosidade, a sinuosidade do curso principal e a razão de textura.

As características do relevo que relacionam as principais medidas do comportamento das altitudes e declividades na principal da bacia, coeficiente de compacidade, fator de forma, índice de circularidade e razão de elongação. 
quanto maior a área, menor a tendência de ocorrer picos de enchentes, devido ao tempo de escoamento para toda a bacia.

Com a delimitação da bacia, obteve-se um valor de área de 3.312,97 $\mathrm{km}^{2}$ e perímetro de $432,48 \mathrm{~km}$ (Tabela 2). O valor de comprimento do eixo principal da bacia foi de $106,06 \mathrm{~km}$, permitindo um conhecimento da forma da bacia, ou seja, se esta é mais alongada ou circular, quando associado a outras características.

Tabela 2. Características e índices geométricos da bacia hidrográfica do Riacho do Navio, em Pernambuco.

\begin{tabular}{lc}
\hline \multicolumn{1}{c}{ CARACTERÍSTICAS GEOMÉTRICAS } & VALOR \\
\hline Área de drenagem (A) & $3.312,97 \mathrm{~km}^{2}$ \\
Perímetro (P) & $432,48 \mathrm{~km}$ \\
Comprimento do eixo (L) & $106,06 \mathrm{~km}$ \\
Coeficiente de compacidade (Kc) & 2,10 \\
Fator de forma (Kf) & 0,29 \\
Índice de circularidade (Ic) & 0,22 \\
Razão de elongação (Re) & 0,61 \\
\hline
\end{tabular}

Por meio da obtenção do coeficiente de compacidade (Kc), 2,10 (Tabela 2), classifica-se a bacia com pouca suscetibilidade a enchentes em condições médias de precipitação. Segundo Villela e Mattos (1975), quanto mais o coeficiente de compacidade se aproxima de 1 , mais circular é a bacia e maior é a sua tendência a gerar enchentes rápidas e acentuadas. Quanto ao fator de forma (Kf), foi obtido um valor de 0,29 , refletindo em uma menor probabilidade de ocorrer na bacia uma chuva intensa que atinja toda sua extensão, comparada com outra bacia de mesma área e menor comprimento axial. Os valores desses índices geométricos foram semelhantes aos observados por Oliveira et al. (2012) ao estudar a bacia hidrográfica do rio Pajeú. Entretanto, Gomes et al. (2020), ao analisar a bacia do rio Exu, localizado na mesorregião do Sertão do Alto rio Pajeú, relataram $\mathrm{Kc}$ de 1,62 e $\mathrm{Kf}$ de 0,39 (indicando formato mais circular).

A caracterização do fator de forma pode ser complementada com o índice de circularidade e a razão de elongação, sendo 0,22 e 0,61, respectivamente, para a bacia hidrográfica do Riacho do Navio (Tabela 2). Esses índices indicam que a bacia não possui formato semelhante ao de uma circunferência, correspondendo, portanto, a uma bacia alongada, corroborando com o valor do fator de forma. Resultados semelhantes foram observados por Andrade et al. (2008) para a bacia hidrográfica do rio Manso-MT, Lopes, Leal e Ramos (2018), para bacia hidrográfica do rio Pontal-PE, e Martins et al. (2021) para a bacia hidrográfica do Ribeirão das Pedras-TO, definindo-as como pouco suscetível a enchentes em condições normais de precipitação.

A bacia hidrográfica do Riacho do Navio apresenta áreas de caatinga arbustiva, com solos rasos e intensos processos de desmatamento e de uso da terra próximo ao curso d'água principal (Araújo Filho et al., 2001; Feitosa, Santos e Araújo, 2011; Ribeiro, 2016), que associados à ocorrência de chuvas intensas no período chuvoso promovem, na realidade, eventos de enchente na região. A estimativa desses índices e o acompanhamento das vazões máximas do Riacho do Navio, a partir de chuvas intensas, seria fundamental para a adoção de medidas mitigadoras do efeito das cheias, como a preservação e/ou recomposição de áreas de preservação permanente (matas ciliares, por exemplo).

\section{Características hidrográficas}

Os índices morfométricos de caracterização hidrográfica são apresentados na Tabela 3. As principais medidas da drenagem da bacia hidrográfica do Riacho do Navio são comprimento do rio principal de $141,32 \mathrm{~km}$ e o comprimento do talvegue do rio principal de 103,97 km. Pode-se verificar também um quantitativo de $1.669,41 \mathrm{~km}$ de comprimento da rede de drenagem em toda a extensão da bacia e 667 unidades de seguimentos de córregos d'água, sendo 334 de primeira ordem $(845,42 \mathrm{~km}), 166 \mathrm{de}$ segunda ordem $(467,88 \mathrm{~km}), 88$ de terceira ordem $(200,88 \mathrm{~km}), 33$ de quarta ordem $(77,64 \mathrm{~km})$ e 46 de quinta ordem $(77,59 \mathrm{~km})$. Essa quantificação vai influenciar diretamente nas características de densidade de drenagem, densidade hidrográfica e razão de textura.

As densidades de drenagem e hidrográfica foram da ordem de $0,50 \mathrm{~km} \mathrm{~km}^{-2}$ e 0,20 segmentos de rios por $\mathrm{km}^{2}$ da bacia, respectivamente (Tabela 3). A densidade de drenagem pode ser classificada no limite entre uma drenagem pobre e regular (Villela e Matos, 1975). Para Milani e Canali (2000), a densidade de drenagem reflete a propriedade de transmissibilidade do terreno e, consequentemente, a suscetibilidade à erosão. Segundo Feitosa, Santos e Araújo (2011), a bacia hidrográfica do rio Pajeú, a qual o Riacho do Navio se insere, possui um baixo desenvolvimento do sistema de drenagem, podendo estar relacionado com as características naturais do clima na região 
Semiárida, com baixos valores de precipitação anual e chuvas concentradas num curto período.

Tabela 3. Características e índices hidrográficos da bacia hidrográfica do Riacho do Navio, em Pernambuco.

\begin{tabular}{|c|c|}
\hline $\begin{array}{l}\text { CARACTERÍSTICAS } \\
\text { HIDROGRÁFICAS }\end{array}$ & VALOR \\
\hline Comprimento da rede de drenagem $(\mathrm{Cr})$ & $1.669,41 \mathrm{~km}$ \\
\hline $\begin{array}{l}\text { Número de segmentos de rios de } 1^{\mathrm{a}} \text { ordem } \\
(\mathrm{Nt})\end{array}$ & 334 \\
\hline Comprimento do rio principal (R) & $141,32 \mathrm{~km}$ \\
\hline $\begin{array}{l}\text { Comprimento do talvegue do rio principal } \\
\text { (Lrp) }\end{array}$ & $103,97 \mathrm{~km}$ \\
\hline Densidade de drenagem (Dd) & $0,50 \mathrm{~km} \mathrm{~km}^{-2}$ \\
\hline Densidade hidrográfica (Dh) & $0,20 \mathrm{~km}^{-2}$ \\
\hline $\begin{array}{l}\text { Extensão média do escoamento superficial } \\
\text { (Lm) }\end{array}$ & $0,50 \mathrm{~km}$ \\
\hline Índice de sinuosidade do rio principal (IS) & $26,43 \%$ \\
\hline Sinuosidade do rio principal (Sin) & 1,36 \\
\hline Razão de textura (T) & $1,54 \mathrm{~km}^{-1}$ \\
\hline
\end{tabular}

Observa-se que o sistema de drenagem da bacia hidrográfica do Riacho do Navio é do tipo dendrítica, de acordo com a classificação de Christofoletti (1980), sendo considerada de quinta ordem (Figura 2), após a análise do mapa de drenagem pelo critério de Strahler (1957). A extensão média do escoamento superficial foi de $0,50 \mathrm{~km}$ e a razão de textura foi de 1,54 segmentos de rios por $\mathrm{km}$ (Tabela 3). Considera-se que, quanto mais ramificada a rede, mais eficiente a drenagem, consequentemente, a água precipitada, depois de ter iniciado o escoamento superficial, vai percorrer uma extensão menor até encontrar um curso d'água (Villela e Matos, 1975). Em relação aos resultados de índice de sinuosidade e sinuosidade do rio principal, os valores obtidos foram de $26,43 \%$ e 1,36 , respectivamente, indicando que o corpo hídrico tem poucas irregularidades e apresenta um padrão retilíneo (Christofoletti, 1980).

Características de relevo

A avaliação das características da bacia hidrográfica do Riacho do Navio permitiu a observação do comportamento espacial da altitude, por meio do MDE (mapa hipsométrico) apresentado na Figura 3.

Com a visualização da Figura 3, fica evidente a relação entre o modelo digital de elevação e a representação da rede de fluxo, o que possibilita a determinação de todas as conectividades a montante e a jusante dos cursos d'água (Lopes, Leal e Ramos, 2018). Essa relação, que é implícita, foi complementada por Medeiros, Ferreira e Ferreira (2009), os quais relataram que em cada célula da estrutura de um MDE contempla um micromapeamento da direção de fluxo, o que torna possível e explícito a direção do fluxo de água para cada área estudada.

$\mathrm{Na}$ Tabela 4 constam as classes hipsométricas na bacia hidrográfica do Riacho do Navio com suas respectivas áreas e porcentagens em relação à área total da bacia. A maior ocorrência por classe de altitude foi de 400 a $500 \mathrm{~m}(51,78 \%)$, enquanto $94,20 \%$ da área tem entre 300 e $600 \mathrm{~m}$.

Tabela 4. Área das classes hipsométricas da bacia hidrográfica do Riacho do Navio, em Pernambuco.

\begin{tabular}{ccc}
\hline Classes hipsométricas $(\mathbf{m})$ & Área $\left(\mathbf{k m}^{2}\right)$ & $\begin{array}{c}\text { Área } \\
(\% \text { do total })\end{array}$ \\
\hline $300-400$ & 671,95 & 20,28 \\
$400-500$ & $1.715,59$ & 51,78 \\
$500-600$ & 733,56 & 22,14 \\
$600-700$ & 140,30 & 4,23 \\
$700-800$ & 41,15 & 1,24 \\
$800-900$ & 8,78 & 0,27 \\
$900-1000$ & 1,03 & 0,03 \\
$>1000$ & 0,61 & 0,02 \\
\hline Área total & $\mathbf{3 . 3 1 2 , 9 7}$ & $\mathbf{1 0 0 , 0 0}$ \\
\hline
\end{tabular}

Tabela 5. Características e índices de caracterização de relevo da bacia hidrográfica do Riacho do Navio, em Pernambuco.

\begin{tabular}{lc}
\hline \multicolumn{1}{c}{ CARACTERÍSTICAS DE RELEVO } & VALOR \\
\hline Altitude máxima da bacia & $1.075,00 \mathrm{~m}$ \\
Altitude média da bacia & $467,37 \mathrm{~m}$ \\
Altitude mínima da bacia & $310,00 \mathrm{~m}$ \\
Amplitude altimétrica $(\Delta \mathrm{H})$ & $765,00 \mathrm{~m}$ \\
Declividade máxima da bacia & $128,40 \%$ \\
Declividade média da bacia & $5,23 \%$ \\
Declividade mínima da bacia & $0,00 \%$ \\
Índice de rugosidade (Ir) & 0,38 \\
Razão de relevo (Rr) & 0,0072 \\
Declividade média do rio principal (S1) & $0,0019 \mathrm{~m} \mathrm{~m}^{-1}$ \\
\hline
\end{tabular}

A altitude máxima da bacia e altitude mínima da bacia foi de $1.075,00 \mathrm{~m}$ e $310 \mathrm{~m}$, respectivamente (Tabela 5). Dessa maneira, o valor encontrado para a amplitude altimétrica foi de 765 $\mathrm{m}$. Essas características de amplitude pouco vão influenciar na quantidade de radiação que a bacia 
hidrográfica intercepta e, por consequência, na evapotranspiração, temperatura e precipitação (Benatti et al., 2015). O índice de rugosidade e a razão de relevo foram de 0,38 e 0,0072 , os quais

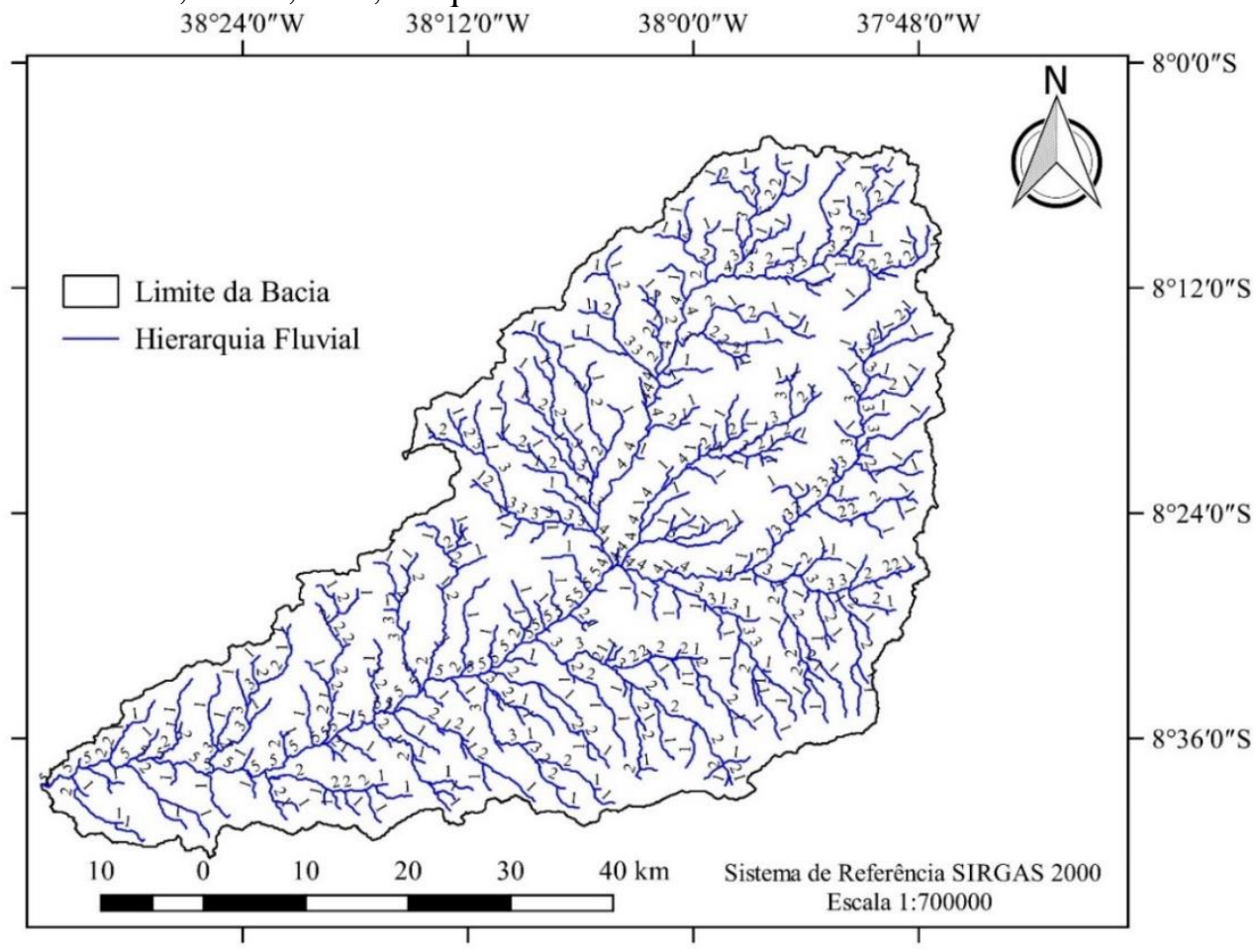

Figura 2. Representação da rede de drenagem e a hierarquia dos cursos d'água da bacia hidrográfica do Riacho do Navio, em Pernambuco.

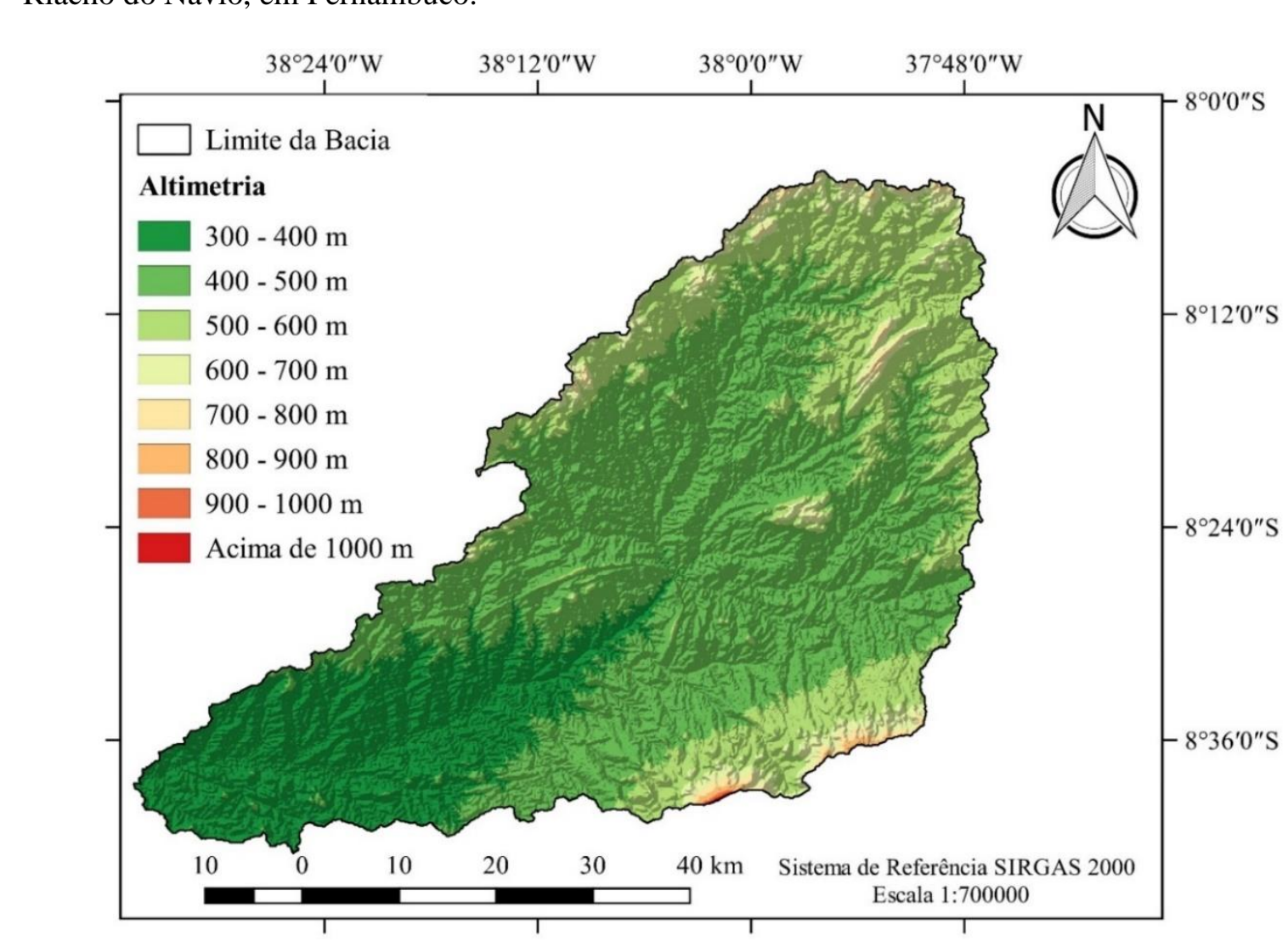

Figura 3. Mapa hipsométrico da bacia hidrográfica do Riacho do Navio, em Pernambuco. são considerados baixos e indicativos de baixa suscetibilidade à ocorrência de enchentes. 
A declividade média do rio principal (S1) é outro aspecto relevante, pois interfere na velocidade do escoamento da água no curso. $\mathrm{Na}$ bacia hidrográfica do Riacho do Navio, a foz do riacho encontra-se na cota de $311 \mathrm{~m}$, e a nascente situa-se na cota de $576 \mathrm{~m}$ de altitude. No intervalo de 141,32 km com sentido de corrente de nordestesudoeste, o Riacho do Navio apresenta uma diferença de nível de $265 \mathrm{~m}$, com valor de declividade média de $0,0019 \mathrm{~m} \mathrm{~m}^{-1}$ (Tabela 5), portanto, mostra tendência a enchentes em razão dessa diferença de altitude e declividade (Vilella e Matos, 1975).

A partir do modelo digital de declividade, observou-se que a declividade máxima foi de $128,40 \%$, a declividade média foi de $5,23 \%$ e mais de $86,61 \%$ da área da bacia apresentou declividades menores que $8 \%$ (Figura 4 e Tabela 6). Desta forma, caracteriza-se a bacia hidrográfica do Riacho do Navio como de relevo plano a suave ondulado, semelhante à classificação encontrada por Lopes, Leal e Ramos (2018) para a bacia hidrográfica do rio Pontal, afluente do Rio São Francisco no Sertão Pernambucano.

Segundo Benatti et al. (2015), a declividade apresentada por uma bacia hidrográfica é um dos fatores que afeta consideravelmente a velocidade do escoamento superficial, reduzindo, assim, a infiltração da água no solo, que, em casos de ausência de cobertura vegetal e elevadas precipitações, potencializam o processo de erosão do solo e a ocorrência de enchentes. Alves et al. (2016) ressaltam que em regiões acima de $45 \%$ de declividade $(0,42 \%$ da bacia hidrográfica do Riacho do Navio) deve ser caracterizada como área de preservação permanente, em conformidade com o novo Código Florestal Brasileiro, Lei no 12.651 (Brasil, 2012).

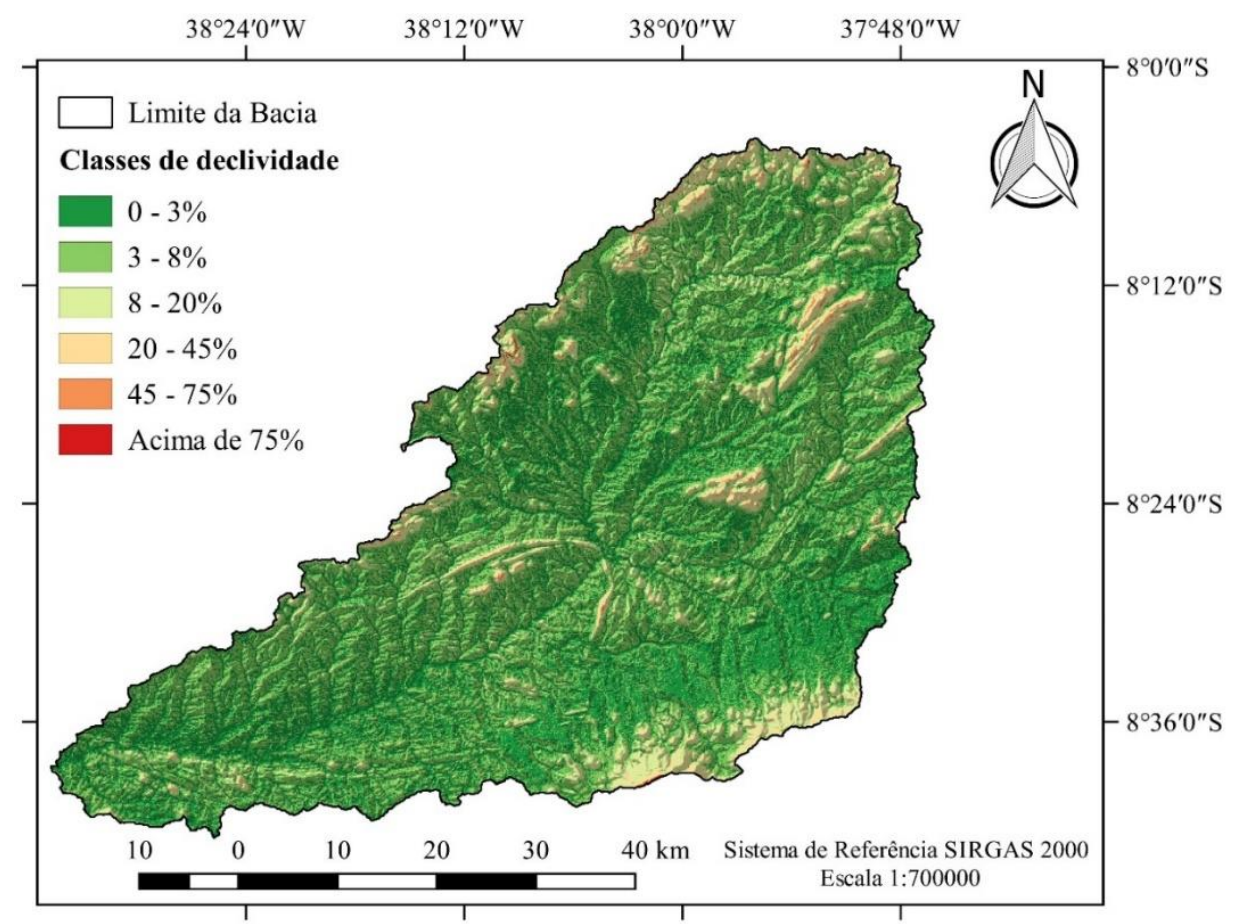

Figura 4. Representação do modelo digital de declividade da Bacia Hidrográfica do Riacho do Navio, em Pernambuco.

Tabela 6. Área das classes de declividade da bacia hidrográfica do Riacho do Navio, em Pernambuco.

\begin{tabular}{lccc}
\hline \multicolumn{1}{c}{ Classes de relevo } & Declividade $(\boldsymbol{\%})$ & Área $\left(\mathbf{k m}^{2}\right)$ & Área $(\%$ do total $)$ \\
\hline Plano & $0-3$ & $1.333,63$ & 40,25 \\
Suave ondulado & $3-8$ & $1.536,07$ & 46,36 \\
Ondulado & $8-20$ & 302,69 & 9,14 \\
Forte ondulado & $20-45$ & 126,84 & 3,83 \\
Montanhoso & $45-75$ & 13,11 & 0,40 \\
Escarpado & $>75$ & 0,65 & 0,02 \\
\hline Área total & & $\mathbf{3 . 3 1 2 , 9 7}$ & $\mathbf{1 0 0 , 0 0}$ \\
\hline
\end{tabular}




\section{Conclusões}

Os índices de coeficiente de compacidade, fator de forma, índice de circularidade, razão de elongação, a densidade de drenagem e a declividade média do relevo indicam que a bacia apresenta uma baixa tendência a enchentes, enquanto que a sinuosidade e a declividade média do álveo podem favorecer a ocorrência de cheias em situações de chuvas intensas.

Por ser uma bacia hidrográfica de relevância agrícola para a região, fazem necessários estudos de uso e ocupação atual do solo, de aptidão agrícola detalhado e o levantamento da qualidade da água.

Os programas QGIS e TauDEM se mostraram ferramentas eficientes no que diz respeito à obtenção das características morfométricas da bacia, de uma forma simples e automatizada, podendo auxiliar na gestão e no gerenciamento de recursos hídricos.

\section{Agradecimentos}

Ao Instituto Federal de Alagoas, pelo custeio do Curso de Especialização Lato Sensu em Georreferenciamento e Geoprocessamento, e a empresa HG2 pela promoção do curso.

\section{Referências}

Alves Sobrinho, T., Oliveira, P.T.S., Rodrigues, D.B.B., Ayres, F.M., 2010. Delimitação automática de bacias hidrográficas utilizando dados SRTM. Engenharia Agrícola 30, 46-57.

Alves, W.S., Scopel, I., Martins, A.P., Morais, W.A., 2016. Análise morfométrica da bacia do Ribeirão das Abóboras, Rio Verde (GO). Revista de Geociências 35, 652-667.

Andrade, N.L.R., Xavier, F.V., Alves, É.C.R.F., Silveira, A., Oliveira, C.U.R, 2008. Caracterização morfométrica e pluviométrica da Bacia do Rio Manso - MT. Revista de Geociências 27, 237-248.

APAC. Agência Pernambucana de Águas e Clima, 2020. Bacias hidrográficas: rio Pajeú. Recife. Disponível em: http://www.apac.pe.gov.br/pagina.php?page_id $=5 \&$ subpage_id=20. Acesso: 29 fev. 2020 .

Araújo Filho, J.C., Silva, A.B., Silva, F.B.R., Leite, A.P., 2001. Diagnóstico ambiental do município de Floresta, Pernambuco. Rio de Janeiro: Embrapa Solos. (Circular técnica, 10).

Benatti, D.P., Tonello, K.C., Leite, E.L., Faria, L.C., 2015. Morfometria, uso e ocupação do solo de uma microbacia em Sete Barras, São Paulo. Irriga 20, 21-32.
Botelho, R.G.M., Silva, A.S., 2004. Bacia hidrográfica e qualidade ambiental. In: Vitte, A.C., Guerra, A.J.T. Reflexões sobre a geografia física no Brasil. Rio de Janeiro: Bertrand Brasil.

Brasil, Lei no 9.433, de 8 de janeiro de 1997. Institui a Política Nacional de Recursos Hídricos, cria o Sistema Nacional de Gerenciamento de Recursos Hídricos, regulamenta o inciso XIX do art. 21 da Constituição Federal, e altera o art. $1^{\circ}$ da Lei $n^{\circ}$ 8.001 , de 13 de março de 1990, que modificou a Lei $\mathrm{n}^{\circ} 7.990$, de 28 de dezembro de 1989. Diário Oficial da República Federativa do Brasil. Pode Executivo, Brasília, DF, 8 janeiro 1997. Disponível em: http://www.planalto.gov.br/ccivil_03/LEIS/L9 433.htm. Acesso: 29 fev. 2020.

Brasil, Lei $\mathrm{n}^{\circ}$ 12.651, de 25 de maio de 2012. Dispõe sobre a proteção da vegetação nativa; altera as Leis $n^{\circ} \mathrm{S} 6.938$, de 31 de agosto de 1981, 9.393, de 19 de dezembro de 1996, e 11.428 , de 22 de dezembro de 2006; revoga as Leis $\mathrm{n}^{\circ}$ s 4.771 , de 15 de setembro de 1965 , e 7.754 , de 14 de abril de 1989 , e a Medida Provisória ${ }^{\circ} 2.166-67$, de 24 de agosto de 2001; e dá outras providências. Diário Oficial da República Federativa do Brasil. Pode Executivo, Brasília, DF, 23 maio 2012. Disponível em: http://www.planalto.gov.br/ccivil_03/_ato2011 -2014/2012/lei/112651.htm. Acesso: $29 \mathrm{fev}$. 2020.

Cadier, E., 1994. Hidrologia das pequenas bacias do Nordeste Semi-árido: transposição hidrológica. Recife: SUDENE, DPG, PRN, HME. 448 p. (Hidrologia, 31).

Christofoletti, A., 1969. Análise morfométrica das bacias hidrográficas. Notícias Geomorfológicas 18, 35-64.

Christofoletti, A., 1980. Geomorfologia. 2. ed. São Paulo: Edgard Blücher. 200 p.

Costa, F.R., Souza, R.F., Silva, S.M.P., 2016. Análise comparativa de metodologias aplicadas à delimitação da bacia hidrográfica do Rio Doce - RN. Sociedade \& Natureza 28, 429-442.

Falcão, T.C.C., Leal, J.M., 1980. Estudo hidroquímico da bacia do Riacho do Navio-PE. In: CONGRESSO BRASILEIRO DE ÁGUAS SUBTERRÂANEAS, 1., 1980, Recife. Anais... Recife: ABAS, 1980. Disponível em: https://aguassubterraneas.abas.org/asubterranea s/article/view/23953/16007. Acesso: 29 fev. 2020. 
Feitosa, A., Santos, B., Araújo, M.S.B., 2011. Caracterização Morfométrica e identificação de Áreas Susceptíveis a Erosão na Bacia do Rio Pajeú, PE: o Estudo de Caso da Bacia do Rio Pajeú/PE. Revista Brasileira de Geografia Física 4, 820-836.

Fernandes, F., Oliveira, M.S.C., Rocha, F.A., 2018. Análise das características morfométricas da bacia hidrográfica do rio de Ondas, BA. Revista Científica Multidisciplinar Núcleo do Conhecimento 2, 55-71.

Ferreira, P.S., Gomes, V.P., Santos, A.M., Morais, Y.C.B., Miranda, R.Q., Ferreira, J.M.S., Galvíncio, J.D., 2014. Análise do cenário de suscetibilidade à desertificação na bacia hidrográfica do rio Pajeú - Estado de Pernambuco. Scientia Plena 10, 105401.

Flenniken, J., Stuglik, S., Iannone, B., 2020. "Quantum GIS (QGIS): An Introduction to a Free Alternative to More Costly GIS Platforms". EDIS 2020 2, 7.

França, G.V., 1968. Interpretação fotográfica de bacias e de redes de drenagem aplicada a solos da região de Piracicaba. 151 f. Tese (Doutorado) - Escola Superior de Agricultura "Luiz de Queiroz", Universidade de São Paulo.

Girão, R.S., Vicens, R.S., Fernandes, P.J.F., Barbalho, L.V., 2019. Avaliação da acurácia vertical de modelos digitais de elevação (MDEs) para o estado do rio de janeiro através de algoritmos de automatização. Revista Caminhos de Geografia 20, 72-79.

Gomes, C., Piscoya, V.C., Cavalcante, D.M., Santos, I.G.O., Cantalice, J.R.B., 2020. Bacia hidrográfica do Riacho Exú, semiárido pernambucano: caracterização hidromorfológica. Ciência Agrícola 18, 37-42.

Horton, R.E., 1945. Erosional development of streams and their drainage basins: hydrophysical approach to quantitative morphology. Geological Society of America Bulletin 56, 275-370.

Lima, W. P., 1969. Manejo de bacias hidrográficas. Piracicaba: ESALQ/Departamento de Silvicultura. $18 \mathrm{p}$.

Lopes, I., Leal, B.G., Ramos, C.M.C., 2018. Caracterização morfométrica de bacia hidrográfica no semiárido de Pernambuco através de dados SRTM em softwares livre. Journal of Hyperspectral Remote Sensing 8, 3140.

Martins, D.D.S., Camargo, R.V., Maciel, G.F., Serra, J.C.V., Zukoswki Junior, J.Ca., 2021. Caracterização morfométrica da bacia hidrográfica do Ribeirão das Pedras no município de Palmas - TO. Revista Aidis de Ingeniería y Ciencias Ambientales. Investigación, Desarrollo y Práctica 14, 377391.

Medeiros, L.C., Ferreira, N.C., Ferreira, L.G., 2009. Avaliação de modelos digitais de elevação para delimitação automática de bacias hidrográficas. Revista Brasileira da Cartografia 61, 137-151.

Milani, J.R., Canali, N.E., 2000. O sistema hidrográfico do rio Matinhos: uma análise morfométrica. Raega - O Espago Geográfico em Análise 4, 139-152.

Miranda, E.E. (Coord.)., 2005. Brasil em Relevo. Campinas: Embrapa Monitoramento por Satélite. Disponível em: http://www.relevobr.cnpm.embrapa.br. Acesso: 29 fev. 2020.

Müller, V.C., 1953. A quantitative geomorphology study of drainage basin characteristic in the Clinch Mountain Area. n. 3. New York: Virginia and Tennesse/Dept. of Geology. p. 30. Nouvelot, J.F., Ferreira, P.A.S., Cadier, E., 1979. Bacia representativa do Riacho do Navio. Recife: $\quad$ SUDENE/DRN/Divisão de Hidrometeorologia. (Hidrologia, 6).

Oliveira, S.D., Silva, M.T., Sousa, E.P., Silva, V.P.R., 2012. Determinação automática de parâmetros morfométricos da bacia hidrográfica do rio Pajeú-PE a partir de MDE. In: WORKSHOP INTERNACIONAL SOBRE ÁGUA NO SEMIÁRIDO BRASILEIRO, 1., 2012, Campina Grande. Anais... Campina Grande: UFCG. Disponível em: http://editorarealize.com.br/revistas/aguanosem iarido/trabalhos/Modalidade_4datahora_11_11 _2013_19_10_01_idinscrito_438_99a0121df8 6f10492f744f2c5df3285a.pdf. Acesso: 29 fev. 2020.

Pontes, J.I., Melo, M.F.O., Lima, V.N., Alcântara, L.A., 2019. Pernambuco tridimensional: potencialidade de geração de produtos cartográficos de apoio a gestão de bacias hidrográficas. In: SIMPÓSIO BRASILEIRO DE SENSORIAMENTO REMOTO, 19., 2019, Santos. Anais... Santos: INPE. Disponível em: https://proceedings.science/proceedings/10006 3/_papers/97532/download/abstract_file1?lang =en. Acesso: 29 fev. 2020 .

QGIS, 2020. Quantum Gis: um sistema de informação geográfica livre e aberto. Disponível em: https://qgis.org/pt_BR/site/. Acesso: 29 fev. 2020.

Rennó, C.D., Nobre, A.D., Cuartas, L.A., Soares, J.V., Hodnett, M.G., Tomasella, J., Waterloo, 
M., 2008. A new terrain descriptor using SRTM-DEM: Mapping terra-firme rainforest environments in Amazonia. Remote Sensing of Environment 112, 3469-3481.

Ribeiro, E.P., 2016. Mudanças ambientais e desertificação na bacia hidrográfica do rio Pajeú. 178 f. Tese (Doutorado em Geografia) Universidade Federal de Pernambuco, Recife.

Rocha, P.C., Santos, A.A., 2018. Análise hidrológica em bacias hidrográficas. Mercator 17, e17025.

Rodrigues, A.C.F., Silva, C.W.G., Rodrigues, E.S.R., Galvão, S.R.S., Caldas, A.M., 2018. Caracterização morfométrica da bacia hidrográfica do Rio Terra Nova - PE. Revista Semiárido De Visu 8, 3-14.

Sánchez, B.L.M., Chávez, E.S., Gonzalez, A.Z.D., 2019. Cartografia das paisagens com sistemas de informação geográfica como base para o diagnóstico geoecológico da bacia hidrográfica do rio Ariguanabo (Cuba). Revista da Associação Nacional de Pós-graduação e Pesquisa em Geografia 15, 169-194.

Schimitt, A., Moreira, C.R., 2015. Manejo e gestão de bacia hidrográfica utilizando o software Quantum-GIS. Revista Cultivando o Saber Edição Especial, 125-137.

Schumm, S.A., 1963. Sinuosity of alluvial rivers on the great plains. Geological Society of America Bulletin 74, 1089-1100.

Silva, A.C.C., Mariani, L., González, R.H.A., 2012. Fundamentos da gestão territorial para recursos hídricos e caracterização de bacias hidrográficas: unidade 1. Agência Nacional das Águas - ANA. Curso de Gestão Territorial para Recursos Hídricos com Software Livre de Código Aberto. Disponível em: https://capacitacao.ead.unesp.br/images/stories /MOOCS/GestaoRHCA/materiais/Unidade1.p df. Acesso: 29 fev. 2020.
Silva, G.C., Almeida, F.P., Almeida, R.T.S., Mesquita, M., Alves Junior, J., 2018. Caracterização morfométrica da bacia hidrográfica do Riacho Rangel-Piauí, Brasil. Enciclopédia Biosfera. 15, 244-255.

Silva, L.P., 2015. Hidrologia: engenharia e meio ambiente. Rio de Janeiro: Elsevier. 330 p.

Smith, K.G., 1950. Standars for grading texture of erosional topography. American Journal of Science 248, 655-668.

Souza, E.G.F., 2019. Prognóstico da demanda hídrica do Açude Barra do Juá e Riacho do Navio, em Floresta-PE, frente à Transposição do Rio São Francisco. 66 f. Monografia (Graduação em Engenharia Civil) Universidade Federal de Alagoas, Delmiro Gouveia.

Strahler, A.N., 1957. Quantitative Analysis of Watershed Geomorphology. Transactions American Geophysical Union 38, 913-920.

Tarboton, D.G., 2020. Terrain Analysis Using Digital Elevation Models (TauDEM). Disponível:

http://hydrology.usu.edu/taudem/taudem5/inde x.html. Acesso: 29 fev. 2020.

Toniolo, B.P., Oliveira, R.A., Lourenço, R.W., Silva, D.C.C., 2021. indicadores morfométricos como instrumento de gestão da bacia hidrográfica do rio Cotia (SP). Holos Environment 21, 282-302.

Tucci, C.E.M., 2015. Hidrologia: ciência e aplicação. 4. ed. Porto Alegre: UFRGS/ABRH. $944 \mathrm{p}$.

Villela, S.M., Mattos, A., 1975. Hidrologia aplicada. São Paulo: McGraw-Hill do Brasil. $245 \mathrm{p}$. 